\title{
SEQUÊNCIA DE ENSINO INVESTIGATIVA: \\ PROBLEMATIZANDO AULAS DE CIÊNCIAS NOS ANOS \\ INICIAIS COM CONTEÚDOS DE ELETRICIDADE
}

\section{SEQUENCE OF INVESTIGATIVE EDUCATION: QUESTIONING SCIENCE CLASSES IN EARLY YEARS WITH ELECTRICITY CONTENTS}

\author{
Lidiany Bezerra Silva de Azevêdo \\ Universidade Federal de Alagoas / lidybezerra@bol.com.br \\ Prof.Dr. Elton Casado Fireman \\ Universidade Federal de Alagoas / eltonfireman@yahoo.com.br
}

\begin{abstract}
Resumo
Este artigo tem como propósito discutir a temática de eletricidade nos primeiros anos do Ensino fundamental, pois acreditamos que o aluno deste cedo já deve ser estimulado a aprender os conteúdos de física e especialmente um tema de suma importância, que faz parte do cotidiano das crianças. Sendo assim, desenvolvemos uma sequência de ensino investigativa, abordando os conteúdos de eletricidade, visto que os Parâmetros Curriculares Nacionais do Ensino de Ciências consideram importante a presença destes conteúdos no ensino fundamental. Diante disso, a pesquisa proposta será de natureza qualitativa, tipo pesquisa ação, desenvolvida em uma turma do $5^{\circ}$ ano do ensino fundamental, sendo o local de pesquisa uma Escola do Município de Palmeira dos Índios no estado de Alagoas. Como instrumento de coleta de dados, utilizamos questionários e gravações em áudio. Para análises de dados, utilizaremos a análise de conteúdos baseados em alguns indicadores de Alfabetização cientifica propostos por Sasseron e Carvalho (2008). Os resultados apontaram que o ensino por investigação é uma metodologia que proporciona ao aluno um aprendizado eficaz e que as práticas investigativas contribuem para que os alunos possam se alfabetizar cientificamente.
\end{abstract}

Palavras-chave: Eletricidade. Conhecimento físico. Sequência de ensino investigativa.

\begin{abstract}
This article aims to discuss the subject of electricity in the first years of elementary school, because we believe that the student of this early should be encouraged to learn the contents of physics and especially this subject that is of the utmost importance, since it is part of the Of children. Thus, we developed a sequence of research teaching, addressing the contents of electricity, since the National Curricular Parameters of Science Teaching consider the presence of these contents in elementary education important. In view of this, the proposed research will be of a qualitative nature, type research action, developed in a
\end{abstract}


class of the 5th year of elementary school, being the research site a School of the Municipality of Palmeira dos Índios. As an instrument of data collection, we used questionnaires And audio recordings. For data analysis, we will use content analysis based on some indicators of Scientific Literacy proposed by Sasseron and Carvalho (2008). The results pointed out that Research Teaching is a methodology that provides the student with an effective and That investigative practices help students to become scientifically literate.

Keywords: Electricity. Physical knowledge. Sequence of investigative teaching

\section{Introdução}

Sabe-se que o ensino da Eletricidade é condição essencial, para o aluno da Educação Básica e deve ser iniciado com alguns conceitos básicos já nos anos iniciais. Sendo assim, o Ensino da Eletricidade não é conteúdo especifico dos Anos Inicias do ensino do Ensino fundamental, porém de acordo com os Parâmetros Curriculares Nacionais (1997), o ensino fundamental é dividido por dois ciclos de Aprendizagem, e no contexto atual,o $1^{\circ}$ ciclo inicia-se no $1^{\circ}$ ao $3^{\circ}$ ano e $02^{\circ}$ ciclo do $4^{\circ}$ ao $5^{\circ}$ ano.Nessa perspectiva,os conteúdos são organizados em blocos temáticos,sendo estes divididos em quatro:ambiente, ser humano e saúde,recursos tecnológicos e terra e universo.A pretensão de se trabalhar em blocos se dar pelo fato de se almejar uma aprendizagem ampla e contextualizada e não assuntos meramente isolados.

Sendo assim, é de suma importância a abordagem desses temas no ensino fundamental, pois o intuito é a promoção de uma aprendizagem de qualidade, além de possibilitar ao aluno a utilização e a compreensão dos recursos tecnológicos, visto que o tema está expandindo consideravelmente o que implica na necessidade da escola desde cedo cumprir o seu papel, na busca de conceitos mais práticos.

No entanto, é premente que os professores sejam preparados para as atividades e que discutam questões diretamente relacionadas com a sociedade, no sentido de estimular os alunos a compreender quais as circunstâncias que cada momento histórico representa para as Ciências, por isso, a necessidade de cada vez mais aproximar o conhecimento científico e tecnológico do contexto da sala de aula. Assim, consideramos importante já introduzir essas discussões nos anos iniciais, visto que, com o advento da tecnologia não há como negar que as crianças têm nos surpreendido constantemente com suas descobertas e curiosidades.

É como esse entendimento que o tema de eletricidade, é tratado como um conteúdo a ser abordado nos anos iniciais que poderá promover uma reflexão relacionada aos temas do cotidiano. Com isso, inserido no bloco dos Recursos Tecnológicos, também assume relevante importância, quando nos PCNs (Parâmetros Curriculares Nacionais, 1997) explícita: "São exemplos de interesse da Física a construção de modelos e experimentos em eletro-eletrônica, magnetismo, acústica, óptica e mecânica (circuitos elétricos, campainhas, máquinas fotográficas, motores, chuveiro, torneira, rádio e pilha, etc.)" (grifo nosso). 
Desse modo, o tema de Eletricidade, sem dúvidas pode ser um conteúdo que estimulará as crianças, pois faz parte do seu cotidiano e o professor poderá proporcionar atividades lúdicas e investigativas que buscará uma aproximação com a realidade da mesma. Sendo assim, ao debruçarmos, sobre os blocos temáticos percebemos que no primeiro ciclo não há uma abordagem a respeito do tema de Eletricidade, porém acreditamos que neste ciclo as crianças já podem entrar em contato com esses conceitos e inclusive serem estimuladas a prática da investigação em sala de aula.

Em síntese, o professor deve entender que os conteúdos não se esgotam apenas na dimensão conceitual se faz necessário promover uma mudança significativa nos alunos dos anos iniciais. Sem dúvidas, os Parâmetros Curriculares de Ciências Naturais oferecem esse leque de orientações que estimulará os saberes que estão intrínsecos na aprendizagem dos alunos, e o conteúdo de eletricidade juntamente com práticas investigativas será de grande valia, visto que já é algo que faz parte do cotidiano das crianças nos anos iniciais. Assim, é premente a realização de SEIS (Sequências de Ensino Investigativas) com o tema de eletricidade no sentido de proporcionar o contato com o conhecimento físico já nos primeiros anos do ensino fundamental.

Por esse motivo, esperamos que essa pesquisa sirva de referencial teórico para os profissionais da área da educação e para os que estão em processo de formação, especialmente para aqueles que lecionam nos primeiros anos do ensino fundamental. É importante salientar, que não pretendemos, neste trabalho, expor uma receita pronta e acabada, pois o professor deve ter autonomia para decidir qual a melhor estratégia didática para desenvolver a aprendizagem de seus alunos.

Assim, a pretensão é propor uma metodologia que possa desenvolver no aluno uma aprendizagem prazerosa e atender aos nossos anseios que é a promoção da Alfabetização Científica. Por essa razão escolhemos o nosso problema de pesquisa: Como a metodologia de Ensino de Ciências por investigação com a utilização dos conceitos básicos de eletricidade poderá ser uma estratégia eficaz para a promoção da Alfabetização Científica nos anos iniciais do ensino fundamental?

\section{Sequência Didática - repensando estratégias para a aprendizagem da Eletricidade nos anos iniciais}

Ao se pensar em aulas de Ciências nos primeiros anos do ensino fundamental, percebemos que os conteúdos propostos não apresentam um olhar investigativo, mas sim algo repetitivo sem nenhuma aproximação com a realidade do aluno, ou seja, os conteúdos são explanados na maioria das vezes no que vem exposto nos livros didáticos o que não condiz com o cotidiano em que o aluno está inserido.

Sendo assim, é premente a necessidade de contribuir para a melhoria das aulas de Ciências Naturais, no sentido de promover um ambiente investigativo em sala de aula em que proporcione ao aluno conhecimentos do mundo científico, pois o que se percebe nas aulas de Ciências nos anos iniciais são conteúdos voltados com certa frequência à área de Biologia. 
É nesse contexto que propomos e planejamos uma SEI (Sequência de ensino investigativa) de acordo com os aportes teóricos de Carvalho (2013). A referida autora busca estratégias pedagógicas na tentativa de aproximar o conhecimento físico e estimulá-los a prática da investigação, tão capital nessa idade. Porém não podemos propor algo distante da maturidade da criança. A sugestão são atividades que possam instigá-los a adentrar na cultura científica e propiciar um ambiente investigativo na sala de aula.

Carvalho (2013, p.09) reconhece que "não há expectativa de que os alunos vão pensar ou se comportar como cientistas, pois eles não têm idade, nem conhecimentos específicos nem desenvoltura para o uso das ferramentas científicas para tal realização" (CARVALHO, 2013, p.09), ou seja, o importante é conduzi-los a construção dos primeiros conceitos científicos. É com esse entendimento, que (BRITO e FIREMAN, 2014, p.65) nos alerta:

[...] não cabe ao professor dos primeiros Anos do Ensino Fundamental exigir das crianças que dêem explicações cientificas totalmente coerentes para a lógica adulta, pois os alunos desse nível escolar, em contato diário com a linguagem das Ciências constroem, paulatinamente, novas (re) significações que vão tornando o entendimento mais completo e substancial.

Percebemos que os conteúdos de "Eletricidade" apesar de serem conteúdos pouco explorados nos primeiros anos escolares, estão presentes no cotidiano; é um conceito primordial para a promoção da Alfabetização Científica, uma vez que busca explicar importantes eventos da natureza, além de contribuir significativamente para a qualidade de vida das pessoas.

É importante ressaltar que a problematização no ensino de ciências é de grande relevância, uma vez que proporciona ao aluno a construção do conhecimento, pois nessa fase de escolarização muitas são as curiosidades, por isso, cabe a proposição de metodologias que estimulem a cultura científica, além de motivá-los a buscarem respostas para o problema proposto. Como bem argumenta (BACHELARD,1996) "[...] Todo conhecimento é resposta a uma questão. Se não houver questão, não pode haver um conhecimento científico. Nada é dado tudo é construído [...]"

Foi com um olhar atento a estes conceitos que construímos uma Sequência Didática, embasados na proposta teórica de Carvalho (2013, p.11-12), quando estabelece ações para o planejamento do problema experimental estabelecendo algumas etapas definidas como SEI,são elas: Etapa da construção e distribuição do material experimental e proposição do problema pelo professor; Etapa da resolução do problema pelos alunos; Etapa de sistematização dos conhecimentos elaborados nos grupos; Etapa de escrever e desenhar.

Nessa percepção, selecionamos alguns conteúdos de cunho pedagógico que explanam a Eletricidade de maneira Lúdica. Selecionamos alguns vídeos como: $\mathrm{O}$ episódio da Série de Onde vem a Energia Elétrica? Um vídeo educativo de uma personagem infantil chamada Kika que norteará os alunos a respeito da origem da Eletricidade, $\mathrm{O}$ episódio o mundo de Beckmam,um série criada desde os anos 90 que tem 
o propósito de ensinar ciências de forma didática tendo um ator americano no papel de professor.Assim esta série trará um conhecimento mais aprofundado de Eletricidade com a explicação de Circuitos Elétricos bem como a Fábula da Disney Ben e Eu, atentando para a importância dos aspectos históricos dos conteúdos de Eletricidade,bem como a tecnologia desde os primeiros anos do ensino Fundamental. ${ }^{1}$

Para tanto, escolhemos alguns conteúdos para compor esse leque de conhecimentos inerentes a temática. Assim, a sequência didática nos termos de Zabala (1998, p.18) trata de "um conjunto de atividades ordenadas, estruturadas e articuladas para a realização de certos objetivos educacionais, que têm um princípio e um fim conhecidos tanto pelos professores quanto pelos alunos".

Nessa perspectiva, a atividade investigativa requer um melhor direcionamento do tema que será abordado, pois o desafio é tornar a sala de aula um ambiente investigativo. Porém, é preciso que o professor também se aproprie destas estratégias, mas infelizmente não é esta a realidade que temos presenciado.

Balizados nesse pensamento Bizzo (2009, p.96), esclarece que "As aulas de ciências podem ser desenvolvidas com atividades experimentais mais sem sofisticação de laboratórios equipados [...]", ou seja, o autor deixa claro que não precisa de muita coisa para que possamos tornar a sala de aula um espaço investigativo, até por que nossas escolas não oferecem condições suficientes para as atividades práticas tendo o professor que desenvolvê-las de acordo com a realidade apresentada.

Com isso, as atividades investigativas podem acontecer de formas diversificadas como estamos propondo na sequência didática, ou seja, com o uso de vários recursos, tais como: vídeos, revistas infantis e experimentos para um melhor esclarecimento do tema, visto que, o processo de ensino e aprendizagem tem de acontecer com o uso desta gama de recursos, considerando que o ritmo de aprendizagem de cada aluno depende dos recursos que são apresentados em sala de aula.

Para propor uma atividade investigativa não precisa necessariamente ser um experimento, o importante é impulsioná-los a resolver um problema proposto. De acordo com esse questionamento, Sasseron (2013, p.43) argumenta que em uma atividade investigativa "[...] pode ocorrer qualquer tipo de atividade que se realize, não estando condicionada a acontecer somente em aulas experimentais. Assim, a leitura de um texto pode ser uma atividade investigativa tanto quanto o experimento de laboratório [...]".

Os conteúdos que propomos para essa sequência foram três recursos audiovisuais com conteúdos de Eletricidade, visto que, esses recursos são utilizados no sentido de aprofundar o conteúdo abordado, porém, não devem substituir de forma alguma o conteúdo abordado. Nesse ínterim, (SANTOS, 2010, p.27) explicita a importância dos recursos audiovisuais quando considera ser "uma forma de acesso ao conhecimento e muita significativa, cabendo ao professor ao término do vídeo desenvolver um trabalho que possa aperfeiçoar a aprendizagem do aluno."

\footnotetext{
${ }^{1}$ Esses conteúdos nortearam a sequência didática, na qual propomos nesta pesquisa, pois buscou-se desenvolver atividades diversificadas para um melhor aproveitamento do processo ensino e aprendizagem do aluno.
} 
Outro recurso que optamos por trabalhar na sequência didática foi a revista educativa: A turma da Mônica e a Energia Elétrica, além de ser um recurso lúdico e prazeroso para o aluno, também assume importante papel no incentivo a leitura, pois não devemos delegar esse trabalho somente a Língua Portuguesa, mas associar a leitura a outras disciplinas.

Com esse entendimento, a inserção da revista educativa é relevante, pois além de conscientizá-los sobre a importância da Energia elétrica para o cotidiano, buscamos essa autonomia na leitura. Assim, o conteúdo ficará mais compreensível, (SEDANO,2013, p.77) defendemos a proposta de inserir a leitura nos conteúdos de Ciências sendo o objetivo "[...] formar o leitor autônomo e competente deve estar pareado com uma metodologia de ensino que busque a formação tanto da autonomia como das competências intelectuais".

No tocante a essa reflexão, não resta dúvidas que a história em quadrinhos é um recurso que contribui para as aulas de Ciências, sendo utilizado como conteúdo procedimental. Esse material é de grande valia para a prática educativa na medida que propõe um ensino mais dinâmico nos Anos Iniciais do Ensino fundamental e traz esta aproximação com o conhecimento científico ao abordar estas temáticas.

O quadro a seguir traz a proposta da Sequência Didática, embasados na proposta Carvalho (2013), bem como a sugestão de atividades lúdicas com a utilização dos recursos já citados ao longo deste capítulo, além da prática investigativa de circuitos elétricos. A pretensão desta sequência é saber: a metodologia de ensino por investigação com a utilização de conceitos básicos de eletricidade promove a Alfabetização Científica? O que a pesquisa busca é que o aluno possa desenvolver suas capacidades cognitivas, indicadores e habilidades que convergem para torna-se um individuo alfabetizado cientificamente.

Quadro 1: Sequência Didática sobre o Ensino da Eletricidade

\section{SEQUENCIA DIDÁTICA: CONCEITOS BÁSICOS DE ELETRICIDADE}

\section{SÉRIE: 5 ANO DO ENSINO FUNDAMENTAL}

\section{OBJETIVOS GERAIS:}

$\checkmark$ Utilizar conceitos científicos básicos para a explicação de conceitos de Eletricidade;

$\checkmark$ Desenvolver a leitura de maneira prazerosa por meio da revista educativa: A turma da Mônica e a Energia Elétrica;

$\checkmark$ Aprofundar os conceitos de Eletricidade com atividades práticas de circuitos elétricos e experimentos eletrostáticos; 

$\checkmark$ Mostrar a importância da "Eletricidade" no cotidiano;
$\checkmark$ Compreender o surgimento da energia Elétrica por meio de Vídeos da Série "De onde vem"?
$\checkmark$ Entender o funcionamento dos Circuitos pelo vídeo do episódio 7 de Eletricidade do Mundo de Beakman;
$\checkmark$ Mostrar as relações da Ciência com a sociedade, a tecnologia e a vida cotidiana de quem faz Ciência com base na Fábula Disney Ben e Eu, atentando para a importância de conteúdos de História e Filosofia das Ciências, desde os primeiros anos do Ensino Fundamental;
$\checkmark$ Compreender e desmitificar a natureza e o papel da ciência, observando suas influências no dia-a-dia do cientista, bem como, na sociedade em sua volta;
$\checkmark$ Incentivar com base nas interações em grupo a resolução do problema nas atividades de experimentação;
$\checkmark$ Estimular a leitura e a escrita após a resolução das atividades;

CONTEÚDO: Conceitos Básicos de Eletricidade e a Sequência de Ensino investigativa de Circuitos Elétricos - SEl.

TEMPO ESTIMADO: Duas aulas com duração de quatro horas cada.

OBJETIVOS A SEREM ALCANÇADOS NESTA SEQUÊNCIA: Compreender conceitos básicos de eletricidade; Estimular a leitura e a escrita por meio de gibis; Estimular o trabalho em grupo; Desenvolver a habilidade de tentar resolver o problema proposto na investigação de circuitos elétricos e eletrostática; Conscientizar sobre os riscos que a Energia Elétrica pode causar quando não são tomados os devidos cuidados; Entender como a Ciência faz parte do cotidiano; Estimular a prática da experimentação e fazê-los perceber que existem diferentes formas de gerar energia; proporcionar uma aproximação com o conhecimento científico no intuito de desenvolver habilidades inerentes a Alfabetização Científica.

1. AULA

$1^{\circ}$ ETAPA- ENTENDENDO CONCEITOS BÁSICOS DE ELETRICIDADE

$1^{\circ}$ MOMENTO 
- Nesse primeiro momento o propósito será verificar o conhecimento inicial sobre o assunto. Será distribuído um questionário com algumas perguntas objetivas e subjetivas sobre alguns conceitos básicos. Nessa atividade eles terão oportunidade de levantar hipóteses sobre o assunto;

- Assistir a Fábula Disney Ben e Eu, atentando para a importância de conteúdos de História e Filosofia das Ciências desde os primeiros anos do ensino Fundamental;

\section{$2^{\circ}$ MOMENTO}

- Realizar uma série de experimentos eletrostáticos, tais como: O canudo que ao ser atritado no papel toalha ficará grudado na parede, tentar colar papel picado no canudo, atrito no cabelo, o canudo giratório ao ser colocado em um copo descartável com um canudo. Proporcionar este momento na tentativa de explicar conceitos de Eletrostática para que eles já comecem a compreender;

- Para sintetizar o conhecimento e aprofundar o conteúdo, assistir a primeira parte do vídeo da Série de onde vem? "De onde vem a energia elétrica"? "De onde vem o trovão"?

- Promover uma socialização no intuito de debater sobre os vídeos e os experimentos eletrostáticos;

- Ao término das atividades pedir que eles façam o registro das atividades da aula, na intenção de estimular e escrita e a criatividade dos alunos;

$2^{\circ}$ AULA

\section{ENTENDENDO A MONTAGEM DE CIRCUITOS ELÉTRICOS}

\section{$1^{\circ}$ MOMENTO: A PROPOSIÇÃO DO PROBLEMA}

- Neste primeiro momento, serão distribuídas cópias da revista "A turma da Mônica e a Energia Elétrica" na perspectiva de estimular a leitura dos alunos;

- Quando as leituras forem concluídas, fazer um circulo para uma roda de conversa procurando compreender o entendimento dos alunos em relação à leitura da revista,foi elaborado um questionário para direcionar a discussão;

- Entender o funcionamento dos Circuitos, assistir o vídeo episódio 7 de Eletricidade do Mundo de Beakman;

- Após o momento da leitura, propor a seguinte demonstração investigativa: Será distribuído o material experimental em pequenos grupos; 


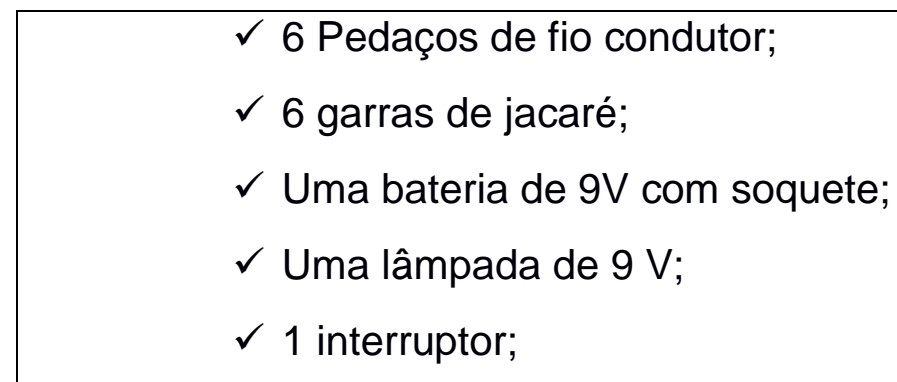

- Após a distribuição do material experimental, fazer a proposição do seguinte problema: Como fazer para ascender as lâmpadas de maneiras diferentes utilizando esses materiais?

\section{$2^{\circ}$ MOMENTO: RESOLVENDO O PROBLEMA PROPOSTO}

- Observar se eles estão conseguindo resolver o problema e escutá-los no levantamento de hipóteses, ou seja, se as lâmpadas estão acendendo;

\section{$3^{\circ}$ MOMENTO - SISTEMATIZAÇÃO DO CONHECIMENTO ELABORADO PELO GRUPO}

- Após conseguir o efeito desejado, o material experimental será recolhido;

- Organizar os alunos em um grande círculo para instigá-los a expor suas concepções sobre o experimento estimulando sempre a participação de todos;

- Fazer as seguintes indagações: Como vocês conseguiram ascender as lâmpadas? De quantas maneiras diferentes podemos acendê-las?

- Incentivar os alunos para expor suas ideias;

- Escutá-los atentamente, pois nessa etapa eles farão um relato e ilustrarão com desenhos o que aprenderam da investigação vivenciada;

- Organizar as falas para que todos possam se expressar;

$4^{\circ}$ MOMENTO- ETAPA DA SISTEMATIZAÇÃO INDIVIDUAL DO CONHECIMENTO

- Solicitar que eles escrevam um texto e desenhem as etapas da investigação, demonstrando o Porquê de ter dado certo; 


\section{Resultados e discussões dos dados}

Para as análises dos dados, tomaremos como norte a SEI aplicada em duas etapas, realizadas em seis momentos, em que foram feitas as transcrições das falas gravadas em vídeo, bem como as análises de algumas partes da escrita que serão colocadas na integra apenas serão corrigidos alguns erros ortográficos e logo após faremos o levantamento de algumas categorias propostas por Sasseron e Carvalho (2008) na qual buscaremos alguns indicadores da Alfabetização Científica.

Com o propósito de preservar a identidade identificamos os alunos com a letra $A$ seguidas de números e os pesquisadores com a letra $P$. Seguindo as etapas da sequência didática, no primeiro momento aplicamos um questionário inicial em que todas as perguntas foram abertas, pois queríamos verificar as ideias iniciais com relação aos conceitos básicos de eletricidade.

Após o término do questionário colocamos os seguintes vídeos: a fábula da Disney Ben e Eu, De onde vem a energia elétrica e De onde vem o trovão? O intuito foi mostrar a importância da história e filosofia das ciências e estreitar a aproximação com a eletricidade, conhecendo com mais detalhes tanto a história da eletricidade quanto os fenômenos que ocasionam o seu surgimento. Notamos que os vídeos chamaram a atenção das crianças, pois ficaram muita atentas e após o termino fizemos uma discussão com o propósito de saber o entendimento deles.

Baseados nas argumentações, percebemos que os discentes conseguiram com o vídeo assimilar os conceitos básicos de eletricidade na medida que eles já conseguem mesmo de maneira pontual eles expor o que assistiram, percebe-se que como foi 0 primeiro contato interativo eles ainda estavam tímidos, mas foi um momento que chamou a atenção das crianças. Isso, mostra-nos como o uso do vídeo pode possibilitar ao aluno uma aprendizagem mais lúdica e atrativa.

Sendo assim, após as discussões realizamos uma série de experimentos eletrostáticos, tais como: o canudo ao ser atritado no papel que ficará grudado na parede, pedimos para eles tentarem colar papel picado no canudo, atrito no cabelo, um canudo perpendicular no copo descartável. Estas atividades provocaram nos alunos um momento de grande euforia e prazer, pois nunca tiveram a oportunidade de vivenciar algo parecido a agitação foi tamanha que não conseguimos captar os áudios dos vídeos.

A esse respeito Bizzo (2012, p.96) traz algumas considerações sobre a prática de experimentação e ressalta que "existe uma motivação natural por aulas que estejam dirigidas a enfrentar desafios e a investigar diversos aspectos da natureza sobre os quais a criança tem, naturalmente, grande interesse. "

Para ilustrar esse momento as figuras abaixo retratam os momentos de experimentação, eles vibravam cada vez que conseguiam. Para Bizzo (2012) as aulas de ciências podem ser desenvolvidas com atividades experimentais mais sem a sofisticação de laboratórios equipados, os quais poucas escolas de fato possuem [...]. A ideia do autor é bastante pertinente, pois comprovamos que com poucos recursos podemos realizar aulas práticas de ciência e promover momentos de investigação no espaço da sala-deaula de acordo com a realidade apresentada. 


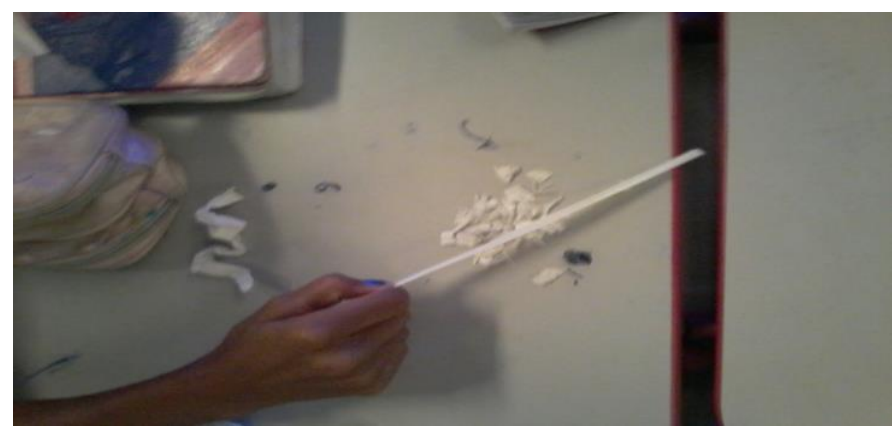

Figura 1: Atrair papel picado ao ser atritado com o canudo.

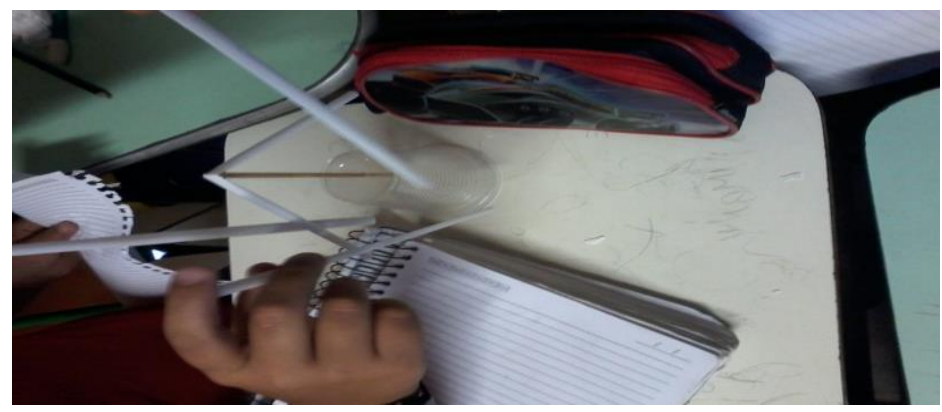

Figura 2: Experimento do canudo giratório ao ser atritado na folha.

Diante dessa proposta, e ao concluírem as atividades solicitamos que eles fizessem os registros escritos e ilustrassem com os desenhos relatando as atividades desta aula. Ao analisarmos a escrita e as ilustrações percebemos a dificuldade dos alunos em relatar o que vivenciaram, a maioria apenas demonstrou com desenhos e quando escreviam não sabiam argumentar, grande parte expressou a satisfação em realizar as atividades e gostariam que tivesse mais vezes. Vejamos abaixo os registros:

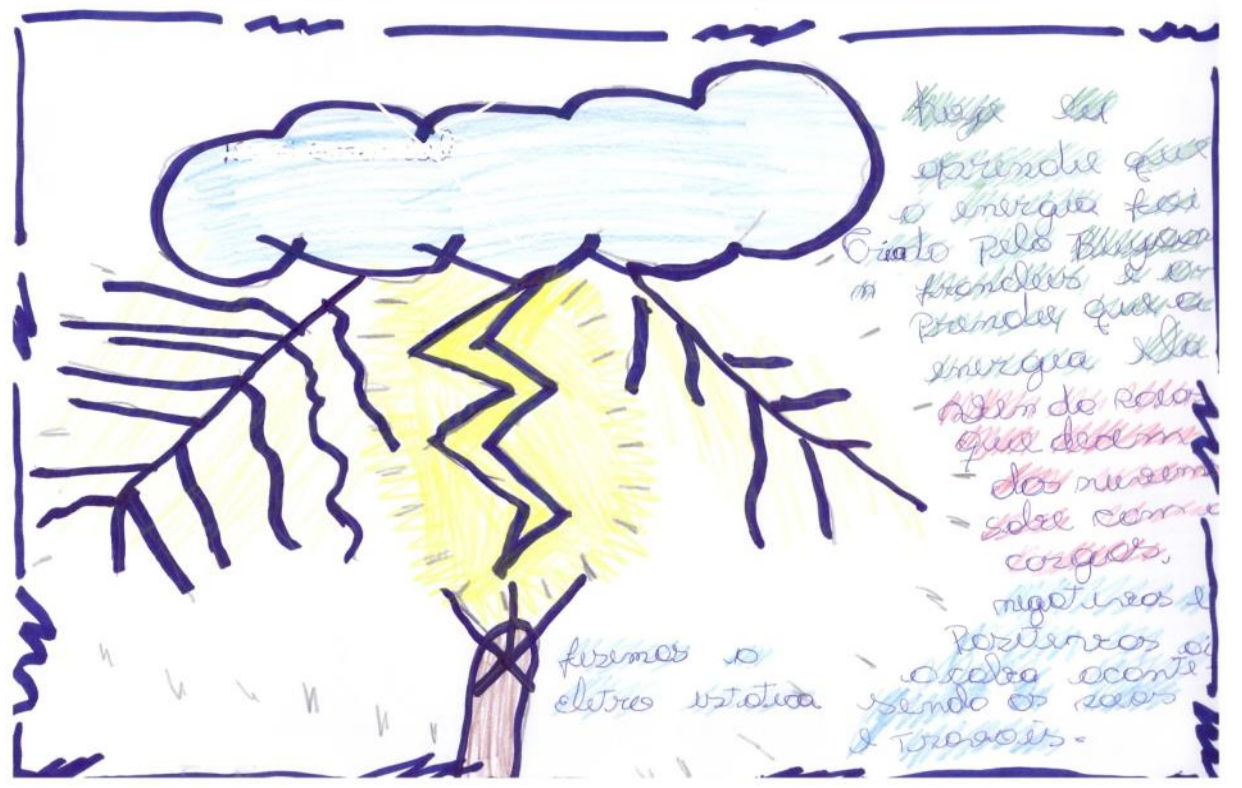

Figura 3: Registros escritos do primeiro dia da sequência didática 
Pelo registro percebemos que o aluno conseguiu sistematizar o que foi desenvolvido na sala de aula, pois na maioria das vezes na fala oral ele não consegue expressar todas as etapas desenvolvidas, mas na sistematização do conhecimento por meio da escrita e desenho isto torna-se mais evidente e eles conseguem justificar e estabelecer a relação com o cotidiano.A atividade escrita se revela importante,pois se apresenta [...] como um instrumento de aprendizagem que realça a construção pessoal do conhecimento. (CARVALHO, 2013, p.13)

No que se refere a segunda aula da SEI este dia foi direcionado a execução de duas atividades. A primeira foi à leitura da revista a turma da Mônica e a Energia Elétrica e a Segunda foi à experimentação de Circuitos elétricos. No que se refere ao gibi distribuímos cópias para que eles pudessem realizar uma leitura individual e para um melhor direcionamento elaboramos um questionário. A leitura da revista além de estimular a leitura proporciona de maneira lúdica esclarecimentos a respeito da eletricidade bem como conscientização inerente ao desperdício de energia. Um dos momentos após a atividade foi o debate a respeito da interpretação da leitura.

A revista foi uma forma de aproximar o aluno da leitura e interpretação de texto, além de chamar atenção com suas ilustrações e ser uma maneira de alfabetizar o aluno culturalmente, pois muitas escolas não tem acesso a estes materiais pedagógicos e quando tem não utilizam tirando ao aluno a oportunidade de entrar em contato com a cultura científica. Além da revista existem materiais como jornais e revistas científicas que são ótimos recursos para serem explorados. Sendo assim, continuamos nossas atividades sobre circuitos elétricos. Antes de começarmos os experimentos passamos 0 vídeo o mundo de Beakman foi muito esclarecedor, pois proporcionou uma visão geral do que seria o circuito já que de acordo com os conhecimentos prévios eles não tinham muita noção do que de fato seria o circuito.

Como o propósito da pesquisa é promover a Alfabetização científica, devemos incorporar no aluno um espírito científico e desenvolver habilidades que provoque 0 interesse e exponham os conhecimentos já adquiridos, as atividades anteriores já despertaram certo interesse o que impulsionará um melhor desempenho na experimentação de Circuitos elétricos. Carvalho (2013) nos atenta pra essa questão que é com base nesses conhecimentos anteriores e na manipulação do material escolhido que os alunos vão levantar suas hipóteses e testá-las para resolver o problema.

Como nos diz Sasseron e Carvalho (2008, p.337), para o início da Alfabetização Científica é importante que os alunos travem contato com habilidades legitimamente associadas ao trabalho do cientista. As habilidades explicitadas pela autora referem-se ao modo como os alunos reagem ao se depararem com algum problema durante a discussão. Para a resolução do problema de investigação com circuitos elétricos distribuímos os seguintes materias: 6 pedaços de fio condutor, 6 garras de jacaré, uma bateria de $9 \mathrm{~V}$ com soquete, uma lâmpada de $9 \mathrm{~V}$ e um interruptor. Nesse momento dividimos a classe em quatro grupos, todos com os materias nas carteiras e propomos 0 seguinte problema: Como fazer para ascender as lâmpadas de maneiras diferentes? 
Antes de começarmos a investigação fizemos algumas orientações para que eles soubessem os materiais que iriam utilizar. Carvalho (2013) ressalta que nesta etapa a classe e dividida pelo professor em pequenos grupos, distribui o material e propõe 0 problema e confere nos grupos se todos entenderam o problema ao ser resolvido. A autora nos alerta que temos que ter cuidado para não falar a resposta, pois retira a possibilidade do aluno pensar.

Após a apresentação do problema passamos para a resolução, ou seja, o momento que os alunos levantaram as hipóteses e tentaram chegar a alguma solução. $O$ importante nessa etapa é que eles explorem o material e tentem resolver, na fase que eles se encontram (Anos iniciais) o que mais vai interessar são as ações manipulativas do que os conceitos em si.

Os grupos tiveram algumas dificuldades de ascender as lâmpadas do circuito, devido aos problemas que tivemos com o vídeo não conseguimos captar as falas do áudio, porém auxiliamos no que foi necessário sem falar a resposta da experimentação.Percebemos,que mesmo diante das dificuldades e das várias tentativas que convergiam ao erro os alunos não desistiram do experimento e além disso desenvolveram inúmeras habilidades,como: organização de ideias, manipulação dos materiais, levantamento de hipóteses e interação. Com relação ao erro no levantamento de hipóteses relacionada a etapa da resolução do problema Carvalho (2013, p.11-12) esclarece:

É a partir das hipóteses - das ideias -dos alunos que quando testadas experimentalmente deram certo que eles terão a oportunidade de construir o conhecimento. As hipóteses que quando testadas não deram certo também são muito importantes nessa construção, pois é a partir do erro o que não deu certo - que os alunos têm confiança no que é certo, eliminando as variáveis que não interferem na resolução do problema. $O$ erro ensina... e muito.

As figuras revelam os circuitos montados:

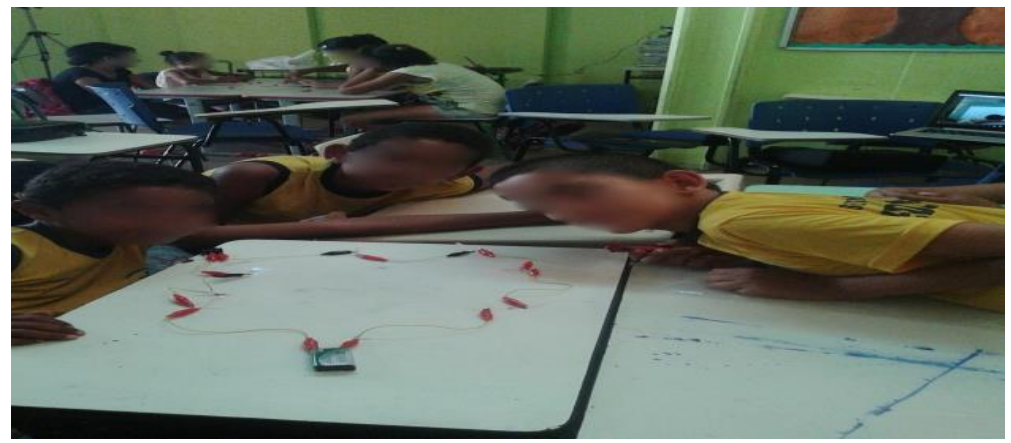

Figura 6: Momento que o grupo conseguiu montar o circuito

O sentimento de satisfação e prazer foram visíveis nos alunos ao conseguirem ascender as lâmpadas e montar o circuito, a figura acima mostra o primeiro grupo que conseguiu resolver o problema proposto. Esse foi um momento crucial, pois encararam o 
desafio e juntos conseguiram separar as variáveis que interferem das que não interferem na resolução do problema.

Resolvida a etapa da experimentação outro momento foi a passagem da ação manipulativa para a ação intelectual fator importante na qual estimula os alunos a expor o que de fato aprenderam na prática, sabemos que no contexto escolar tem alunos que se expõe mais que outros na oralidade, porém acreditamos que foi bastante proveitoso para toda a turma,pois foi o momento de explorar os materiais e solucionar o que propomos, no grupo eles ficam a vontade para expor o que pensam,já com o professor muitas vezes essa exposição é limitada. Com as carteiras organizadas em círculo realizamos uma roda de conversa para testarmos as hipóteses que foram levantadas com a realização da investigação.

Carvalho (2013, p.03) argumenta a esse respeito:

[...] passagem da ação manipulativa para a construção do intelectual do conteúdo deve ser feita agora com o professor, quando este leva o aluno, por meio de série de pequenas perguntas e questões a tomar consciência de como o problema foi resolvido e porque deu certo a partir de suas próprias ações.

É evidente que durante as aulas de ciências na qual visam comprovar se o processo de Alfabetização Científica está sendo desenvolvido entre os alunos são encontrados alguns indicadores, pois durante um trabalho investigativo, várias habilidades são desenvolvidas e os alunos diante do problema desempenham o papel de pesquisadores.

Para as autoras (Sasseron e Carvalho, 2008) os indicadores têm a função de nos mostrar algumas destrezas que devem ser trabalhadas quando se deseja colocar a AC em processo de construção entre os alunos. Os indicadores ligados à procura da situação analisada em que surgem em etapas finais das discussões, como é o caso das transcrições abaixo é o momento de expor o que eles aprenderam na investigação. Fazem parte deste grupo: levantamento de hipótese, teste de hipótese, justificativa, previsão e explicação. Segue algumas transcrições da roda de conversa:

$P$ : Pessoal, e ai o que foi que vocês aprenderam com o experimento?

A: Foi bom. (resposta coletiva)

A4: muitas coisas.

$\mathrm{P}$ : Como vocês conseguiram ascender às cinco?

A: Todos falam de uma só vez. (barulho)

$P$ : Silêncio pessoal, fala um de cada vez!

P: Foi fácil pra vocês?

A2: não.

A4: Pra mim foi.

P: E aí o que vocês aprenderam na prática relacionado com o mundo de Beakman? 

A: todos ficam em silêncio...

A1: Que os circuitos podem ser passados pelo fio e pelos metais, mas não pode ser tudo de uma só vez.

A explicação de $A 1$ revela alguns indicadores da $A C$, o primeiro refere-se a construção de uma explicação e o uso do raciocínio lógico sobre circuitos elétricos, é normal que as explicações neste fase não sejam coerentes ao mundo científico, mas aos poucos eles vão estruturando o pensamento. Vejamos:

P: O primeiro circuito que vocês construíram qual foi o segredo para consegui?

A4: É colocar é......dois jacarés é....

P: não entendi repete

A4: não tem o interruptor agente estava colocando a garra de jacaré separado só que é pra botar junto.

$P$ : A ta, no local do interruptor, as perninhas né? As conexões se abrem as duas próximas.

$P$ : Mais o que mais, o que é que deu errado que vocês não estavam conseguindo fazer? Conseguiu, depois não conseguiu o que foi que houve?

A1: Foi porque nós não conseguimos fazer a volta dela, que ela foi até a lâmpada só que da lâmpada não conseguiu voltar para a bateria aí ela não ascendeu, aí todos nós tiramos.... Esqueci o nome daquele ferrinho.

$\mathrm{P}:$ Resistência?

A1: Resistência, ela queimou por que não tinha dado a volta aí desconectou.

Foi notório nestas discussões que as crianças levantaram várias hipóteses até encontrar a solução para o problema, organizaram as ideias, usaram o raciocínio lógico e justificaram como é o caso de A1 "Ela queimou por que não tinha dado a volta aí desconectou'.

$\mathrm{P}$ : Agora eu quero de acordo com a experiência que vocês fizeram hoje eu queria que escrevessem e desenhassem ta jóia? Então vão colocar o relato de vocês da experiência, tá certo?

\section{A: Certo (resposta coletiva)}

Concluída a sistematização do conhecimento coletivo iniciamos a etapa de escrever e desenhar, ou seja, a sistematização individual do conhecimento. Esse momento é de grande preponderância, pois eles por si só organizam as ideias e expõem o que de fato chamou atenção nas atividades, além de desenvolver a escrita desenvolvem a criatividade a partir dos desenhos. Sobre essa etapa (Carvalho et al,2013, p.13) argumenta:

[..] O professor deve, nesse momento, pedir que eles escrevam e desenhem sobre o que aprenderam na aula.O diálogo e a escrita são atividades complementares,mais fundamentais nas aulas de Ciências, 
pois,como o diálogo é importante para gerar,clarificar,compartilhar e distribuir ideias entre os alunos,o uso da escrita se apresenta como instrumento de aprendizagem [...]

Dessa forma, as crianças desenvolveram o momento de sistematização do conhecimento individual, dos 18 alunos que realizaram a atividade selecionamos alguns relatos para demonstrar como as crianças desenvolveram o raciocínio após o experimento da SEl. Notamos nesta etapa a mesma situação vivenciada nas etapas anteriores quando solicitávamos que escrevessem e desenhassem a maioria apenas ilustra com desenhos e relata a sua satisfação na realização das atividades. Vejamos abaixo alguns relatos que mais nos chamaram atenção:

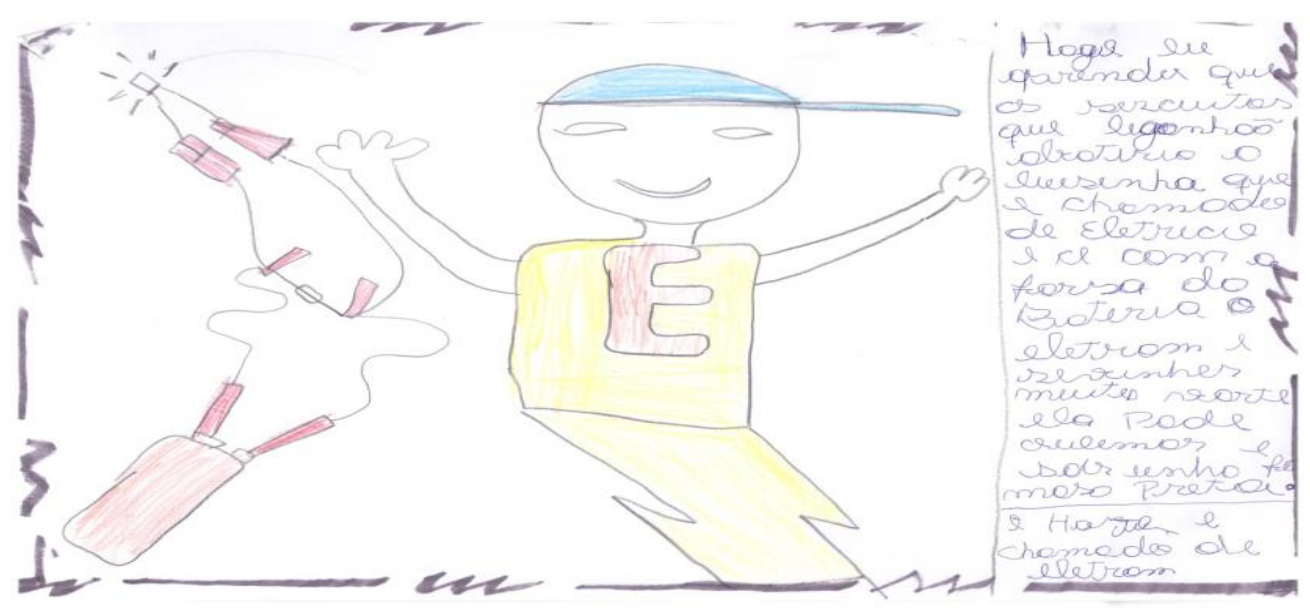

Figura 7: Relato na etapa da sistematização individual do conhecimento

Além deste aluno desenvolver a criatividade e o raciocínio com o desenho demonstrando do elétron, fica notório que ele desenvolveu várias habilidades e estabeleceu um link com a série $O$ mundo de Beakman. Há neste relato a presença de indicadores da Alfabetização Científica, tais como: Raciocínio lógico, levantamento de hipóteses, explicação e previsão. Isso demonstra como as práticas de investigação nas aulas de Ciências pode contribuir para uma aprendizagem eficaz e desenvolver a autonomia do educando.

Enfim, fica perceptível que a prática da experimentação desenvolveu nos alunos indicadores da Alfabetização Científica, o que nos remete comprovar que a prática do ensino por investigação provoca nos alunos momentos de verdadeiro aprendizado, o que nos faz recomendar para os professores dos Anos Iniciais a presente metodologia nas aulas de Ciências, pois fica claro que os alunos sentem falta da manipulação de materias nesta fase de escolaridade. 


\section{Considerações Finais}

A partir das análises dos dados da pesquisa, foi comprovado com base nas atividades desenvolvidas que o Ensino por investigação é uma metodologia eficaz para a promoção da Alfabetização Científica. Essa afirmação se confirma quando os alunos no decorrer das aulas desenvolvem sua capacidade cognitiva de maneira espontânea sem está atrelado somente a simples decoreba exposta nos livros de ciências.

A pesquisa também nos revelou que as aulas de ciências ficam mais atrativas quando os alunos têm um problema a ser resolvido e tem a oportunidade de manipular os materias isto torna a aula ainda mais prazerosa e, além disso, várias habilidades são desenvolvidas, visto que é nesta fase de escolaridade que a curiosidade está ainda mais aguçada e quando eles são chamados a desenvolver atividades investigativas são desenvolvidas além da parte conceitual a cooperação, o respeito pela opinião no outro e a motivação.

Fica perceptível que foram desenvolvidos indicadores que atendem aos propósitos da Alfabetização Científica tais como: organização de ideias, raciocínio lógico, justificativa, levantamento de hipóteses. Além destes indicadores foram constatadas habilidades como: capacidade de revolver problemas, autonomia, raciocínio, interação e argumentação. Pois é evidente que o ensino por investigação promove a Alfabetização cientifica, que como vimos ao longo desta pesquisa embasados em vários autores, que um indivíduo para ser alfabetizado cientificamente deve está em sintonia com os saberes científicos e que estes saberes possam torna os cidadãos mais conscientes para as diversas situações que venham a surgir.

É notório que a cada etapa da sequência os alunos demonstravam satisfação na realização das atividades, principalmente de experimentação em que foi perceptível que as crianças eram surpreendidas a cada atividade que estava sendo desenvolvida,pois era novidade.Essa confirmação é demonstrada tanto no momento que estava acontecendo a prática quanto nos relatos escritos na qual foi uma oportunidade de sintetizarem suas ideias por meio da escrita,pois muitas vezes alguns apresentam certas dificuldade com a oralidade.

Temos notado que os conteúdos de eletricidade nos últimos anos do ensino fundamental e no ensino médio apresenta-se grandes dificuldades por parte dos alunos, isso nos remete a premissa de que se eles fossem vistos nos primeiros anos do ensino fundamental os discentes não teriam nenhum problema nos últimos anos de escolaridade, pois é preciso reconhecer que é um conteúdo atrelado ao cotidiano.

Foi o que fizemos ao longo da SEI, mostramos a cada etapa com a utilização dos recursos didáticos (gibis, vídeos e experimentações) que a eletricidade está presente no nosso dia-a-dia trazendo sempre para a realidade na qual eles estão inseridos. É por isso, que conseguimos atender aos propósitos que esperávamos chegando ao resultado: 0 ensino por investigação com a utilização de conteúdos básicos de eletricidade é uma metodologia eficaz para a promoção da Alfabetização Científica nos anos iniciais do ensino fundamental. 
Enfim, o ensino por investigação desenvolve nos alunos vários momentos de aprendizagem aproximando ainda mais do saber cientifico e desencadeando indicadores e habilidades que podem tornar o aluno alfabetizado cientificamente, pois as práticas tradicionais não permitem ao aluno a oportunidade de enxergar além do que é estabelecido nos livros didáticos.

\section{Referências}

BRASIL. Secretaria de Educação Média e Tecnológica. Parâmetros Curriculares Nacionais: Ensino Médio. Brasília, 2000.

BRICCIA, Viviane. Sobre a natureza da Ciência e o ensino. In: Ensino de Ciências por investigação: condições para implementação em sala de aula. São Paulo: Cengage Learning, 2013. p.111 - 128

BIZZO, Nelio.Ciências: Fácil ou Difícil? São Paulo: Biruta, 2009

BRITO, Liliane Oliveira; FIREMAN,Elton. Ensino de ciências por investigação: uma estratégia pedagógica para promoção da alfabetização científica nos primeiros anos do ensino fundamental. Disponível em: http://www.ufal.edu.br/ppgecim/disertações-2014 lensino-de-ciencias-por-investigacao-uma-estrategia-pedagogica-para-promocao-da-

alfabetizacao-cientifica-nos-primeiros-anos-do-ensino-fundamental. Acesso:14 de out.2015.

CARVALHO, Anna Maria Pessoa de. Ensino de Ciências por investigação: condições para implementação em sala de aula. São Paulo: Cengage Learning, 2013.

PIZARRO.Mariana Vaitiekunas. Histórias em quadrinhos e o ensino de ciências nas séries iniciais: estabelecendo relações para o ensino de conteúdos curriculares procedimentais.

Disponível

em: http://repositorio.unesp.br/bitstream/handle/11449/90960/pizarro_mv_me_bauru.pdf?sequ ence $=1$. Acessoem:10 set.2015.

SASSERON, Lúcia Helena; CARVALHO, Anna Maria Pessoa de;.Alfabetização Científica: uma revisão bibliográfica. Disponível em:<http://www.if.ufrgs.br/ienci/artigos/Artigo_ID254/v16_n1_a2011.pdf>. Acesso em: 25 jun. 2014

SASSERON, Lúcia Helena; CARVALHO, Anna Maria Pessoa de. Almejando a alfabetização Científica no Ensino Fundamental: A Proposição e a procura de Indicadores do processo. Disponível em: http://www.if.ufrgs.br/ienci/artigos/Artigo_ID199/v13_n3_a2008.pdf .Acesso em: 25 jan. 2016. 
SANTOS, Priscilla Carmona do. A utilização de recursos de ensino deciências:tendências entre 1997 e2007.Disponível em: www.teses.usp.br/teses/disponiveis/.../Dissertacao_Priscilla_Carmona.pdf. Acesso em: 24 out.2015.

SEDANO, Luciana. Ciências e Leitura:um encontro possível. In: Ensino de Ciências por investigação: condições para implementação em sala de aula. São Paulo: Cengage Learning, 2013. P.77-91.

ZABALA, Antoni. A prática educativa: como ensinar. Porto Alegre: Artmed, 1998.

Submissão: 01/12/2016

Aceite: $26 / 05 / 2017$ 